\title{
Clicking Toward Development: Understanding the Role of ICTs for Civil Society
}

\section{Abstract}

The purpose of this article is to analyze, discuss, and assess some of the competing viewpoints and factors regarding the role of new information and communication technologies (ICTs) within civil society. By outlining the various actions that civil society organizations (CSOs) need to take in order to maximize the positive impacts and mitigate the negative consequences that these revolutionary technologies will bring, it will become clear that the employment and utilization of ICTs by civil society has yet to reach an optimal point. However, over the next few decades, while these technologies will inevitably come to transform the development landscape, the hope is that CSOs will fully integrate ICTs into the development process and will come do so with realistic expectations. By adopting an ICT "plan of action," CSOs could better harness the power of these new technologies and, in turn, will be able to more successfully apply them towards the promotion of improved human development.

\section{Introduction: A Light in the Dark?}

It should not be surprising that over the past few years a certain number of civil society organizations (CSOs) may have begun to feel as if their long, arduous, uphill battle for making inroads toward improving the lives of individuals in developing countries was being given an unexpected, yet invaluable, boost. With the advent of new information and communication technologies (ICTs) - including personal, networked computers, mobile telephones, fiber optic cables, the Internet, and email-CSOs could not help but think that the general worldwide information, communication, and knowledge revolution would come to trickle down and positively affect the specific goals they were trying to accomplish in the realm of human development. This optimism compelled CSOs to design their own websites, make policy documents available on-line, and initiate the formation of virtual communities - constituted by individuals with similar interests - by way of email and chat rooms. Additionally, the excitement over the potential uses of ICTs encouraged CSOs to integrate these technologies into the fabric of development programs and projects as well. Not only would it become de rigueur to

provide poor, rural communities with computer workstations and laptops, but the power of connectivity led to the hope that solutions to the problems of poverty, poor health education, and lack of political involvement might just be a few clicks away.

Nevertheless, over the very same time span, this rosy picture has sobered quite a bit. CSOs, and, more importantly donors, have begun to understand that the mere provision of a few iMacs and Dell laptops cannot undo years of marginalization and oppression. In some areas, it is difficult enough to predict when the electricity and power will function, let alone when a high-speed cable modem connection will be installed. Moreover, the potential of using ICTs in political activism - an application that was supposed to act as the "great equalizer" for those individuals previously unable to participate in government and, therefore, usher in a new wave of democracy - has yet to be fully realized. In fact, as Leslie David Simon (2002a) notes in his introduction to Democracy and the Internet, some authoritarian governments, such as those formerly in Afghanistan and Iraq, are working to restrict the use of these technologies, thereby suppressing democratic movements and reasserting their power to block civil society's employment of ICTs in promoting free speech and political involvement. Simon describes how these governments have engaged in a number of subterfuge attempts, including a wholesale banning of the Internet, the filtering and censorship of on-line material, requiring the registration of websites, regulating encryption devices, and even criminalizing certain kinds of Internet or email use..$^{1}$ The point here is that a number of unintended, negative consequences, along with a number of undesirable barriers, have arisen that have hindered the use of ICTs by CSOs and have come to force a reconceptualization of how these new technologies fit into future development schemes.

Because of these growing concerns, the purpose of this article is to analyze, discuss, assess, and clarify competing viewpoints and factors regarding the role of ICTs within civil society 
and to determine various actions that CSOs might be able to take that will mitigate some of the negative consequences that I have started to sketch out above. To start, I will begin by detailing the reasons why ICTs became so attractive to civil society actors in the first place and to evaluate some of the more positive and useful aspects of ICTs for improving human development. Second, I will consider the real pitfalls that have blocked civil society's ability to capture some of the advantages of ICTs and, in turn, have come to reduce their potential for improving development projects and programs. Finally, I will lay out an ICT "plan of action" for civil society and propose a variety of measures that should be undertaken so that additional benefits from these new technologies can be realized. Though I will draw upon a number of examples, I will focus mostly on how these new capabilities affect political involvement, local participation in government, and the push for democracy around the world. In the end, it will become clear that the employment and utilization of ICTs by civil society has yet to reach an optimal point, and it remains to be seen how a number of key variables and unknowns will mature and play themselves out in the coming years.

\section{Potential Salvation: How ICTs Could Rescue the Developing World}

The rise of ICTs has come to herald a new kind of world, a world in which individuals, companies, communities, and governments can become instantaneously, immediately, and directly linked to other individuals, companies, communities, and governments anywhere around the globe. Lying at the heart of globalization, ICTs can be broadly viewed and defined as facilitating "by electronic means the creation, storage, management and dissemination of information." 2 While, strictly speaking, the overall notion of ICTs does include older, more traditional forms of communication-television, radio, faxes, newspapers, and magazines - that have existed throughout most of the $20^{\text {th }}$ century, the meaning of the term has changed and has begun to relate, more specifically, to the various kinds of new, "high" technologies that I listed earlier. Admittedly, as new technologies and modes of communication arise, the characterization of what is considered to be a progressive, advanced, and cutting-edge form of ICT will inevitably change, thereby requiring a continual updating regarding how this term is understood.
At first glance, what is so alluring about the mainstreaming of these modes of gathering and distributing information for civil society is that these technologies appear to emphasize and demonstrate a number of traits and values that mesh well with the development process. Along these lines, a report produced by the Digital Opportunity Initiative (DOI), which is sponsored by the United Nations Development Programme, notes that "ICT can be a powerful enabler of development goals because its unique characteristics dramatically improve communication and the exchange of information to strengthen and create new social and economic networks." 3 Evidently, one of the most central qualities that can bring ICTs inline with certain development goals is the notion that ICTs are "pervasive and cross-cutting," and, therefore, that they "can be applied to the full range of human activity... allowing for tailored solutions - based on personalization and localization - to meet diverse needs." ${ }^{4}$ In short, the very idea that ICTs, and, in particular, the Internet and email, can be used for a number of functions - ranging from reading daily news stories to communicating with family members to distance learning_-implies that developing communities and nations can have nearly instant, all-encompassing access to any kind of information they might ever want.

It is this ability to enter a flexible network of information and knowledge dissemination that was, and still remains, so encouraging to many members of civil society. In her paper "The Development Divide in a Digital Age," Cynthia Hewitt de Alcántara (2001) mentions possibilities that might interest CSOs: for example, she notes that mobile phones can allow for "minute-by-minute monitoring of local elections," thereby leading to the gathering of information that can then be reported over the radio and, in turn, make "a significant difference in the transparency of electoral processes." 5 Moreover, she demonstrates that certain technologies, including satellite television, voice over the Internet, and digital radio, have expanded "the range of programming available to inhabitants of countries whose governments, until recently, could limit television reception to a few state-run channels." ${ }^{6}$ Furthermore, the DOI report describes similar potentials for knowledge sharing and dissemination in the realms of health, education, and economics, including the ability of local doctors to receive disease diagnosis and treatment advice on-line 
from experts in other countries, the ability of local teachers to receive technical and vocational training remotely, and the ability of local businesses to receive information regarding market conditions and best business practices by way of list-servs and electronic updates. Put together, all of these opportunities have led to a declaration by CSOs at the World Summit on the Information Society (WSIS), which notes that "we are conscious that information, knowledge and the means of communication [for developing nations] are available on a magnitude that humankind has never dreamt of in the past." 7

In particular, ICTs have helped local communities and populations participate in government and become more active in pushing for political change. For instance, with respect to direct participation in democracy, Simon (2002a) claims in "Democracy and the Net" that a number of governments are "putting their voting systems online and permitting citizens to communicate directly with legislators." $8 \mathrm{He}$ illustrates this point with the example of Costa Rica, which is attempting to reach $100 \%$ voter turnout by offering on-line balloting by way of computers based in the nation's various schools. Moreover, in addition to allowing CSOs and local citizens to vote, monitor elections, and procure timely news items, Simon also notes that these technologies can allow a government to become more involved with its citizens. In short, Simon claims that "the Net has the power to change the way governments operate- - forcing them to become more democratic [and responsible] in the process." 9 For example, as more and more government documents and proceedings are placed on-line, information regarding how the government works is being "made more easily available to citizens," thereby implying that it "does not have to pass through the filter of a civil servant," which, in turn, reduces the risk that such data could be altered or deleted by a corrupt official. 10

The increased presence of ICTs in the developing world has also initiated a significant trend toward coalition building among CSOs and individuals, on both domestic and international levels. For instance, consider the Kubatana Project of Zimbabwe, which supports "a website portal that provides Zimbabwean civil society organizations with an online presence and a platform to voice their concerns about human rights abuses in their country." 11
Even though all of the participating CSOs are located within Zimbabwe, without the use of ICTs, these disparate, yet ideologically connected, groups would have had little chance of working together, pooling their strengths, and uniting under a common cause. Since the website is hosted outside of the country, www.kubatana.net has allowed over 200 Zimbabwean CSOs to bypass government control of the media and, subsequently, has provided timely and accurate information about the state of human rights abuses in Zimbabwe by way of fact sheets, website links, and even the posting of the diaries of political prisoners.

Along these lines, in "Lessons from Latin America," Javier Corrales (2002) describes how informal social movements banded together by way of e-petitions and web-based networking during the financial crisis in Argentina in 20012002. Corrales notes that "when the [Argentine] government froze bank deposits, hundreds of neighborhood assemblies (asambles barriales) emerged in protest. They created their own website (www.cacerolazo.com), which allowed approximately 180 assemblies to coordinate their activities and post their demands." 12 Apparently, this effort was so successful that city officials in Buenos Aires received, and responded, to nearly four hundred emails a day, all of which complained about or demanded the restoration of a previously canceled service.

Similarly, on an international level, by allowing individuals and groups to communicate with increasing ease across national lines, ICTs are breaking down geographical boundaries and spawning transborder coalitions that can unite under a common, mutual cause. In short, ICTs are able to link different individuals and communities around the world to one another, individuals and communities sharing similar mindsets, beliefs, and value systems. Specifically, the DOI report reinforces this point that new methods of communication will continue to allow democratically inclined CSOs to begin working under a broader perspective and to undertake a more global approach with respect to advocating for democracy, free speech, and human rights. In this regard, DOI claims that "ICT can transcend cultural and linguistic barriers by providing individuals and groups the ability" to integrate their activities with each other and, therefore, coordinate more targeted responses against tyrannical or repressive regimes. ${ }^{13}$ 
Pippa Norris (2004), in "Giving Voice to the Voiceless," supports this notion that "the rise of the Internet may be a particularly important development for the process of democratization" worldwide. ${ }^{14}$ In other words, she claims that in "breaking down the traditional boundaries of space and time," CSOs are able to mobilize ICTs and use them to bring about a diverse range of "oppositional voices, new social movements, and transnational advocacy networks." 15 One well-known use of ICTs in this fashion is how antiglobalization activists around the world were able to coordinate, manage, and plan protests and demonstrations against the World Trade Organization during their meetings in Seattle in 1999 by way of mobile phone text messaging systems. Additionally, Corrales (2002) describes a similar situation by which the labor leaders of the Chiapas rebellion in Mexico have created an international coalition that "routinely conducts e-mail campaigns against [foreign] employers and government agencies" that support companies contributing to the degradation of workers' quality of life in that country. 16 Finally, Hewitt de Alcántara describes how ICTs, by way of on-line videos and chat room discussions, can be used simply to garner support and raise international consciousness about human rights abuses in countries such as China, Myanmar (Burma), and Saudi Arabia. ${ }^{17}$

Overall, it should not be surprising that, ever increasingly, CSOs are encouraged to employ ICTs in some form, whether it be maintaining and preserving international advocacy coalitions, registering complaints with local officials, or participating in democratic change. By opening civic discourse to a wider population and providing transparent, unencumbered access to the inner workings of government, ICTs have assisted in transforming the way previously voiceless, marginalized groups and individuals have come to speak out in support of their own rights and demands. Specifically, the Internet's openness, pervasiveness, and ability to create social networks has allowed, and will continue to allow, for the possibility of achieving human, economic, and political development at an everincreasingly rapid, quickened pace. However, as I will discuss below, the shining promise of ICTs to reach such staggering heights has been tempered in recent years by a number of factors, factors that are inherent not just to ICTs themselves but to the development process as a whole.
Blocking the Path: Barring the Way for ICTs in Development

"The world's poorest two billion people

desperately need healthcare, not laptops." 18 Bill Gates

As the above quotation from Bill Gates demonstrates, it is too simplistic to believe that ICTs will solve all of the problems in the developing world. In fact, while providing an individual with access to a website or an email account might go a long way in raising them out of poverty, supplying them with good health, and helping them choose their governmental representatives, it remains the case that a significant fraction of the world's population does not have the opportunity to engage with and utilize these new forms of technology at all. Recent statistics regarding worldwide Internet use depict that this technology has only penetrated $11.5 \%$ of the total population, with the majority of users located in North America, Europe, East Asia, Australia, and New Zealand. ${ }^{19}$ In Africa, barely $1 \%$ of the population has access to the Internet, and while Internet access has grown the fastest in Latin America, the Caribbean, and the Middle East, these regions account only for about $9 \%$ of worldwide Internet users. ${ }^{20}$

These indicators demonstrate that the development divide between the North and the South is being matched - and, in many cases, exacerbated by - a similar digital divide. As the Civil Society Declaration of the WSIS notes, these "new asymmetries" are being mapped onto "the existing grid of social divides," including "the divide between the North and South, rich and poor, men and women, urban and rural populations," and, most important in the case of ICTs, "those with access to information and those without." ${ }^{21}$ In short, even as ICTs become more pervasive, open, and easily accessible, "the vast majority of humankind has no access to the public domain of global knowledge, a situation that is contributing to the growth of inequality and exploitation of the poorest peoples and communities." 22 Throughout this section, I will analyze a number of reasons for this increasingly severe digital divide, and it will turn out that, not surprisingly, many of these rationales relate, once again, directly to broader issues pertaining to human development.

To start, it should be noted that a main reason why ICTs have yet to reach their full potential for assisting in development is that the infra- 
structure for their use in developing countries is either weak or nonexistent. As I mentioned earlier, most communities lack access to a power supply for simple telephone calls, let alone for a high-speed internet connection. Impoverished individuals can barely afford to buy enough food for their own sustenance, let alone a computer or personal digital assistant. Moreover, even if a village does possess a communal laptop or mobile phone, many individuals do not have enough education or training regarding how to use these technologies, let alone have the time to engage with these devices if this means skipping work, missing a day of harvest, or ignoring a sick family member.

As a report by Robert Curtain (2004) for the Australian Agency for International Development contends, this problem remains pressing when one begins to focus on how organizations - let alone individuals - that are based in developing countries use ICTs. He points out that even Southern CSOs are rarely able to access these kinds of technologies for their own organizational needs. In turn, this inability for organizations in the developing world to engage effectively with ICTs comes to handcuff the ability of CSOs in the developed world to employ these technologies, even though Northern-based organizations generally have access to as many variations of technology as they wish. In fact, Curtain notes that the "main reasons given by development agencies for low use of ICT by agencies in developing countries" range from the somewhat simple, including "lack of equipment, poor infrastructure and limited access to Internet services," to the complex, including constraints of gender roles, rigid managerial control over ICT access, and inhibitions about ... written ... communication." 23

As Curtain identifies, it can be difficult enough for individuals, CSOs, governments, and corporations from developed countries to use ICTs - where issues such as reliable power supplies, infrastructure robustness, and social constraints are less pressing-let alone in developing countries, where these more basic, fundamental concerns are chronic and ever-present.

Clearly, these technical obstacles that arise in developing countries can greatly affect the success or failure of a civil society initiative aimed at using ICTs for the purpose of political activism or participation in government. For example, even though the Kubatana project appears to have effectively helped CSOs in Zimbabwe organize and coordinate a response to the government's human rights abuses, it is unclear how much voice and impact such a project could have internally, within the country, when barely $3.5 \%$ of the Zimbabwean population has Internet access, let alone the fact that political pressure and lack of suitable infrastructure requires that the website be hosted in a more developed nation. ${ }^{24}$ Similarly, while the Cacerolazo project in Argentina appears to have pressed the government to respond to individual concerns and demands, that the Internet has penetrated only $10.9 \%$ of the Argentine population implies that there are a number of groups and individuals that cannot participate, even if participation only means the sending of an email or the logging of an on-line complaint. 25

In addition, these numbers mask the trend that only those financially well-off in a country have access to ICT sources, thereby further indicating that already impoverished, marginalized individuals and communities are shut out of the benefits of these new technologies. As Peter Levine (2000) argues in "The Internet and Civil Society," "People cannot use computers [and ICT in general] effectively unless they have money, skills," and other capabilities that lie at the foundations of human development. 26

In addition to these structural barriers blocking an enhanced position for ICTs in helping to achieve improved development, there are additional ideological critiques that question whether these new technologies and modes of communication are really able to strengthen democracy and improve local political participation. One argument is put forth by the Platform for Communication Rights, "an umbrella group of international nongovernmental organizations and local networks active in media and communications," who contend that the growth of ICTs within an increasingly interconnected, worldwide "information society" are just "another invention of the globalization needs of capital and their supporting governments." 27 This organization has initiated a campaign, entitled Communication Rights in the Information Society (CRIS), in support of the notion that current attempts to spread ICTs and employ them as a central aspect in the development process is simply "window-dressing on the most recent drive to impose a neo-liberal model of communication in every corner of the globe, ... 
driven by the needs of transnational corporations with little more than lip service to real human needs and ever-growing inequities." 28

While CRIS's point is that the push for employing ICTs in development should be viewed as just another seductive method for international conglomerates and their respective governments to further co-opt, control, and deepen the already stark development divide, I am not fully convinced that the exacerbation of the power dynamic between the "haves" and the "have-nots" is the only way ICT involvement in development will play itself out. Clearly, there are a number of corporate and national Goliaths that have, do, and will continue to use ICTs for means of repression and subversion. As mentioned earlier, governments have, do, and will continue to try to ban the Internet or restrict communication with the outside world and, evidently, a number of transnational corporations will resist lowering their prices to help developing communities enjoy the benefits of ICTs, let alone loosen their financial and legal claims to copyrighted and patented material. However, I argue, as the examples of Kubatana, Cacerolazo, and the Chiapas rebellion have demonstrated, that there is at least some "leveling" and equalizing aspect inherent to ICTs, the nature of which will make it increasingly difficult for these corporate and governmental forces to coopt social and political resistance and participatory movements in the future. Admittedly, it is unclear whether ICTs will ever have the ability to make the Davids of the world fully and completely equal to the Goliaths, but I claim that, to a certain degree, these technologies have slowly begun to help initiate this evening-out process.

However, one of the more subtle and prescient critiques arising out of CRIS's position is the notion that, in many cases, civil society incorrectly views these new technologies "as ends in themselves rather than as enabling tools." ${ }^{29}$ Again, the idea here is that ICTs should rightly be deemed as tools to help the development process and not as the end state or goal. In other words, ICTs should be regarded as ways of helping people attain health, money, education, and democracy and not as the overriding purpose of a program or project that then comes to subsume these more vital and essential objectives.

Clearly, it could be quite easy for civil society to fall into this trap of mistaking means with ends. For instance, a project that provides twenty computers for a village with the hope that these machines will reform the lives of the individual inhabitants is bound to fail if more foundational issues, such as transportation access to the center of town, personal security, and basic energy infrastructure, are not addressed as well. The difficulty is that the products of ICTs - computers, mobile phones, and even fax machines and copiers - can be used to provide attractive, alluring photography and publicity opportunities for donors without truly addressing more substantial, long-term problems. These material objects will be able to accomplish little if other issues in development are not addressed in conjunction, issues concerning whether individuals will be able to read or write, whether women will be allowed to use the equipment, and whether regular maintenance will be performed.

From personal experience, while working in a science education outreach project in rural, poor parts of South Africa, I witnessed many situations along these lines. In multiple schools, there were a number of locked storage closets filled with computer hard drives, monitors, and keyboards, all of which were products of some donor's desire to "connect" these institutions to the world at large. However, it was clear that a number of underlying factors were never considered. First, power irregularities in most schools ensured that not even the main, land-line telephones could work. Second, the machines themselves had broken down, and many were either outdated or unfixable. Third, the keyboards and printed instructions were presented solely in English, even though the students mainly spoke Afrikaans, Zulu, or Xhosa. Finally, and most telling, the main reason the hardware was kept locked away is that the teachers were worried that if the computers were left to remain unattended in the classrooms, then they would probably be stolen, damaged, or vandalized.

However, even if CSO projects and programs correctly find a way to use ICTs as tools in the development process, there remains a final barrier working to offset the possible positive impacts of ICTs in development. The complaint here is that these technologies reduce the incentive for individuals and communities to form strong social ties and, therefore, fail to encourage individuals to work together and strive for a common goal. While ICTs can help bridge geographical gaps and bring individuals 
and communities struggling for similar freedoms and possessing similar interests into contact with one another, Levine (2000) offers the counter-argument that ICTs might actually "replace robust, durable, and emotionally satisfying social bonds with superficial and contingent ones." 30 Levine contends that when engaging with ICTs, "we can withhold practically all information about ourselves... we can break off contact at will... and we can shield ourselves from the consequences of what we say," all of which distort one's ability to enter into satisfying relationships with other individuals and may weaken any sense of commonality and togetherness. 31

If such an assessment holds, civil society's ability to effectively use ICTs to promote good governance and democratic change might be diminished, primarily because such an argument implies that community and capacity building are weakened by the presence of these new technologies. For example, if a CSO is trying to bring about a greater understanding of cultural differences and similarities in an ethnically diverse society, then an incessant reliance on ICTs by way of shared websites and chat groups might actually work against the stated goals since the use of these technologies might block the formation of strong interethnic ties. The idea here is that ICTs might not really promote social connection but that they simply create weak, fragile, and quite tenuous bonds that could splinter in times of great stress or duress. With respect to the Cacerolazo project in Argentina, one could argue that if the only outcry the city government of Buenos Aires received during the financial crisis was in the form of email, then it is quite conceivable that officials could simply delete most of these messages and ignore their content. Along these lines, ICTs might actually encourage governments to distance themselves from truly interacting with their citizens, especially since these technological links might only be able to generate superficial, digitally contingent relationships.

I admit that determining the validity of such an argument is challenging. Some might assert that if the best kind of connections CSOs can hope to create in these days of mass electronic communication are superficial, digitally contingent relationships, then perhaps the whole system needs to be dumped and our priorities need to be reevaluated. On the other hand, some might contend that these Internet and email links are better than nothing and should be pursued, regardless of the downfalls. Personally, I am still uncertain regarding how this debate will be settled, especially because it remains to be seen whether ICTs actually strengthen social ties, by encouraging previously unconnected individuals and communities to learn about one other, or weakens social ties, by allowing disinterested citizens or officials to exit any form of public discourse by simply clicking-off and shutting-down.

However, I do support the notion that ICTs alone cannot do the development trick. At some level, real interpersonal engagement by way of human-to-human interaction is necessary to address the development divide, which, in turn, will go a long way in addressing the digital divide. I contend that when making evaluations regarding the appropriateness of new technologies in the context of development, civil society must move away from the dogmatic extremes: while ICTs might not be magic potions to cure all of the world's ills, they are not pointless, useless enterprises that can be easily dismissed. Instead, I argue that ICTs as a group should be recognized as highly-valuable, though still highly-flawed, tools for achieving certain development goals, and, therefore, they must be critically analyzed so that their positive and negative traits can be teased out and better understood.

\section{Changing the Landscape: What Should Civil Society Do?}

Though I have already described a number of the benefits and pitfalls of using ICTs in development, there appear to be a few areas that civil society is capable of addressing so that improvements can be made in how these technologies are applied in the future. Obviously, the following "plan of action" is not a complete, comprehensive list, nor is it the case that these suggestions remain unproblematic. However, the ensuing recommendations could hopefully help civil society prioritize its actions and identify key areas of concern.

First, CSOs need to help improve and build basic technology infrastructure in developing countries prior to introducing high-speed, cutting-edge versions of ICTs to these regions. Simon (2002b) notes that this type of foundational development requires considerations as diverse as "training for professionals," developing "applications in critical areas such as health care, job placement, and food distribution," and 
providing "funding and expertise to build testbeds for public access systems." 32 To be sure, this advice might require CSOs to re-evaluate their already existing strategies and, quite possibly, lead them to understand that it might be beneficial, in a certain case, to help establish energy grids or basic telephone capabilities prior to a DSL Internet connection. Clearly, though a renewed focus on "the basics" of technology might imply that CSOs cannot move ahead with certain kinds of projects as quickly as they would like, it does mean that whatever technologies are employed will rest on a solid, stable infrastructure and, hopefully, will be sustainable and built to last over the long term.

A second role for CSOs in the realm of technology access in the developing world is to become involved, as Hewitt de Alcántara (2001) notes, in "international policy forums that play a major role in determining the likelihood that low-income countries and disadvantaged groups can use ICTs effectively." 33 In particular, CSOs need to fight the growing tendency in the developed world to comprehensively copyright and patent protect information, thereby blocking the free and open use of such innovations in lower income, less technologically advanced regions of the world. As the CRIS campaign argues, civil society needs to exert pressure "at local levels to ensure that IPR [intellectual property regime] legislations respond to social and cultural needs." 34 In addition, CSOs need to ensure that the traditional, indigenous knowledge present in developing communities is not somehow soldoff and copyrighted, thereby reassuring that this cultural heritage cannot be taken away and removed from the public domain. The hope is that CSOs - in addition to working with the World Trade Organization, the International Telecommunications Union, and the World Intellectual Property Organization to reform technology trade regulations, redistribute worldwide telephone revenues, and better organize the digital spectrum, respectively — will also be able to "nurture and promote development-friendly approaches to intellectual creativity, e.g., open source, copyleft, and collective ownership." 35

Third, I contend that in order to reap the full benefits of ICTs in development, CSOs, even those from the developed North, need to become more ICT-literate themselves. This suggestion implies that a significant transformation in organizational culture needs to occur so that $\mathrm{CSO}$ - which, historically, might have shied away from or have been afraid of using these technologies - are no longer intimidated by their presence. In his study on how CSOs attempt to capture the advantages of ICTs, Curtain (2004) discovered that while $90 \%$ of the organizations he consulted used email as a major form of communication, "only a . . . minority of the respondent organizations $(10 \%)$ were making use of a database management application such as financial management software." 36 The point here is that if CSOs are not comfortable employing new forms of communication services, such as video conferencing and electronic newsgroups, internally, then it will be quite challenging for CSOs to promote the use of ICTs in developing communities. Along these lines, CSOs should ensure that their websites are not forums merely used for displaying basic contact information and their mission statements. Instead, CSOs must make certain that these Internet portals become truly interactive experiences, allowing the external world to post comments, access policy documents, and link to other information sites. Only such an improved, internal shift in thinking within CSOs of the developed world will allow for an associated improved, external shift in how these organizations are able to utilize ICTs in the developing world.

Finally, CSOs need to apply political pressure on the leaders of less democratic nations and advocate for the removal of heavy-handed government control and oversight of ICTs. As Norris (2004) claims, whether it be arguing in favor of freedom of the press or supporting the breakup of government-owned communication monopolies, CSOs need to help guarantee that populations in the developing world are offered "widespread access to the mass media" and that excessive legislative oversight of ICTs is not allowed to "reinforce the control of powerful interests and governing authorities." 37 Simon (2006) supports the notion that CSOs undertake an even stronger social advocacy role in this area and, in turn, help to "raise the international temperature to protect free expression and the natural openness of the global Net." 38 Though certain governments have and will continue to try to restrain Internet access, monitor email communication, and restrict chat-room use, CSOs must become committed to incorporating support for such deregulation into their wider mandate of promoting democracy and combating the oppression of free speech. 
In conclusion, though I have analyzed the positive and negative aspects of various ICTs and weighed their promises versus their drawbacks, I still assert that these new technologies will inevitably transform the landscape of development in unknown ways over the next few decades. The idea here is that, hopefully, CSOs will come to not only use ICTs to help foster democracy but that they will do so with realistic expectations. However, the only way such a sensible, practical path can be chosen is if CSOs are wary of the critique that the means, the technologies themselves, cannot and must not be confused with the end state, namely, human development. What is so intriguing is that even newer, as-of-yet unknown varieties of ICTs may come along and offer currently inconceivable possibilities for the developing world. In turn, successive generations of these technologies may carry with them the ability to bridge the existing digital, development divide even quicker than we could ever hope for now. CSOs will play a critical role in helping us move in the direction of such a promising future. Even though, as a Michael Edwards (2004) notes in his book Civil Society, "the rapid expansion in access to information technology [by civil society]...has not yet been [fully] translated into the development of public spheres committed to resolving social and economic problems across societies," I argue that evolution in this direction has already begun. ${ }^{39}$ In the end, the hope is that CSOs, by adopting some kind of ICT "plan of action," will be able to harness the power of these new technologies and, in turn, will be able to apply them toward the promotion of superior international human development.

Evan S. Michelson is a Research Associate at the Woodrow Wilson International Center for Scholars, Washington, D.C., in the Foresight and Governance Project's Project on Emerging Nanotechnologies. He is a Member-at-large of Epsilon Pi Tau.

\section{References}

The Association for Progressive Communications and the Communication Rights in the Information Society, (2003) Involving ICT in Civil Society: World Summit on the Information Society, available at http://www.apc.org/books/policy_wsis_EN.pdf, September 2003, accessed April 17, 2004, pp. $39-40$.

Bridges.org, (2004)"The Kubatana Project of Zimbabwe: Case Study Series on ICT-enable Development," available at http://www.bridges.org/iicd_casestudies/kubatana/index.html, accessed April 19, 2004.

Civil Society Declaration to the World Summit on the Information Society, (2003) "Shaping Information Societies for Human Needs," available at http://www.wsis2005.org/wsis/documents/summit/WSIS-CS-Decl-25-2-04-en.pdf, World Summit on the Information Society, Geneva, Switzerland, December 8, 2003, accessed April 20, 2004.

Corrales, J. (2002) "Lessons from Latin America," in Simon, Leslie David, Democracy and the Internet: Allies or Adversaries? Washington, D.C.: Woodrow Wilson Center Press, pp.30-66.

Curtain, R. (2004) "Information and Communications Technologies: Help or Hindrance?" available at http://www.developmentgateway.com.au/pdf/ict/CurtainICT4DJan04.pdf, Australian Development Gateway, January 13, 2004, accessed on April 19, 2004, p. 11.

de Alcántara, C.H. (2001) “The Development Divide in a Digital Age: An Issues Paper," available at http://www.unrisd.org/80256B3C005BCCF9/httpNetITFramePDF?ReadForm\&parentunid=19B0 B342A4F1CF5B80256B5E0036D99F \&parentdoctype $=$ paper\&netitpath $=80256 \mathrm{~B} 3 \mathrm{C} 005 \mathrm{BCCF} /(\mathrm{h}$ ttpAuxPages)/19B0B342A4F1CF5B80256B5E0036D99F/\$file/hewitt.pdf, Technology, Business, and Society Programme Paper Number 4, United Nations Research Institute for Social Development, August 2001, accessed April 21, 2004.

Digital Opportunity Initiative, (2001) “Creating a Development Dynamic," available at http://www.opt-init.org/framework/DOI-Final-Report.pdf, July 2001, accessed April 19, 2004.

Edwards, M. (2004) Civil Society, Cambridge, UK: Polity Press. 
Helmore E. and McKie, R. (2000) "Gates Loses Faith in Computers," available at The Observer Online, http://observer.guardian.co.uk/print/0,3858,4086462-102275,00.html, published November 5, 2000, accessed April 22, 2004.

“Internet Usage Stats: The Big Picture,” Internet World Stats: Usage and Population Statistics, (2004) available at http://www.internetworldstats.com/stats.htm, accessed April 18, 2004.

“Internet Usage Stats for Africa," Internet World Stats: Usages and Population Statistics, available at http://www.internetworldstats.com/stats1.htm, accessed April 18, 2004, p. 1.

"Internet Usage in South America," Internet World Stats: Usage and Population Statistics, available at, http://www.internetworldstats.com/stats2.htm\#south, accessed April 18, 2004, p. 1.

Levine, P. (2000) "The Internet and Civil Society," in Report from the Institute for Philosophy \& Public Policy, University of Maryland, 20 (4): 1-8.

Norris, P. (2004) "Giving Voice to the Voiceless: Good Governance, Human Development, \& Mass Communication," available at http://ksghome.harvard.edu/ .pnorris.shorenstein.ksg/Acrobat/Pfetsch\%20chapter.pdf, February 16, 2004, accessed April 21, 2004, p. 4.

Simon, L. D. (2002a) "Preface," in Simon, Leslie David, Democracy and the Internet: Allies or Adversaries? Washington, D.C.: Woodrow Wilson Center Press, pp. vii-xii.

Simon, L.D. (2002b) "Conclusion," in Simon, Leslie David, Democracy and the Internet: Allies or Adversaries? Washington, D.C.: Woodrow Wilson Center Press, pp. 96-102.

\section{Notes}

${ }^{1}$ Leslie David Simon, "Preface," in Simon, Leslie David, Democracy and the Internet: Allies or Adversaries? Woodrow Wilson Center Press: Washington, D.C., 2002, pp. vii-xii, p. viii.

2 Richard Curtain, "Information and Communications Technologies: Help or Hindrance?" available at http://www.developmentgateway.com.au/pdf/ict/CurtainICT4DJan04.pdf, Australian Development Gateway, January 13, 2004, accessed on April 19, 2004, p. 11.

3 Digital Opportunity Initiative, “Creating a Development Dynamic," available at http://www.optinit.org/framework/DOI-Final-Report.pdf, July 2001, accessed April 19, 2004, p. 9.

${ }^{4}$ Digital Opportunity Initiative, p. 9.

${ }^{5}$ Cynthia Hewitt de Alcántara, "The Development Divide in a Digital Age: An Issues Paper," available at http://www.unrisd.org/80256B3C005BCCF9/httpNetITFramePDF?ReadForm\&parentunid=19B0B342A4F1CF5B80256B5E0036D99F \& parentdoctype=paper\&netitpath $=80256 \mathrm{~B} 3 \mathrm{C} 005 \mathrm{~B}$ CCF9/(httpAuxPages)/19B0B342A4F1CF5B80256B5E0036D99F/\$file/hewitt.pdf, Technology, Business, and Society Programme Paper Number 4, United Nations Research Institute for Social Development, August 2001, accessed April 21, 2004, p. vi.

${ }^{6}$ Hewitt de Alcántara, p. vi.

${ }^{7}$ Civil Society Declaration to the World Summit on the Information Society, "Shaping Information Societies for Human Needs," available at http://www.wsis2005.org/wsis/documents/summit/WSISCS-Decl-25-2-04-en.pdf, World Summit on the Information Society, Geneva, Switzerland, December 8, 2003, accessed April 20, 2004, p. 4.

8 Simon, "Democracy and the Net: A Virtuous Circle?" in Democracy and the Internet, pp. 1-29, p. 13.

9 Simon, "Democracy and the Net: A Virtuous Circle?" p. 12.

10 Simon, "Democracy and the Net: A Virtuous Circle?" p. 12.

11 Bridges.org, "The Kubatana Project of Zimbabwe: Case Study Series on ICT-enable Development," available at http://www.bridges.org/iicd_casestudies/kubatana/index.html, accessed April 19, 2004, p. 1.

12 Javier Corrales, "Lessons from Latin America," in Democracy and the Internet, pp. 30-66, pp. 3940. 
13 Digital Opportunity Initiative, p. 10.

14 Pippa Norris, "Giving Voice to the Voiceless: Good Governance, Human Development, \& Mass Communication," available at http://ksghome.harvard.edu/ .pnorris.shorenstein.ksg/Acrobat/Pfetsch\%20chapter.pdf, February 16, 2004, accessed April 21, 2004, p. 4.

15 Norris, p. 4.

16 Corrales, p. 40.

17 Hewitt de Alcántara, p. 27.

18 Edward Helmore and Robin McKie, "Gates Loses Faith in Computers," available at The Observer Online, http://observer.guardian.co.uk/print/0,3858,4086462-102275,00.html, published November 5, 2000, accessed April 22, 2004.

19 “Internet Usage Stats: The Big Picture," Internet World Stats: Usage and Population Statistics, available at http://www.internetworldstats.com/stats.htm, accessed April 18, 2004, p. 1.

20 "Internet Usage Stats: The Big Picture," p. 1.

21 Civil Society Declaration, p. 6.

22 Civil Society Declaration, p. 15.

23 Curtain, p. 23.

24 "Internet Usage Stats for Africa," Internet World Stats: Usages and Population Statistics, available at http://www.internetworldstats.com/stats1.htm, accessed April 18, 204, p. 1.

25 "Internet Usage in South America," Internet World Stats: Usage and Population Statistics, available at, http://www.internetworldstats.com/stats2.htm\#south, accessed April 18, 2004, p. 1.

26 Peter Levine, "The Internet and Civil Society," in Report from the Institute for Philosophy \& Public Policy, University of Maryland, Volume 20, Number 4, Fall 200, pp. 1-8, p. 1.

27 The Association for Progressive Communications and the Communication Rights in the Information Society, Involving ICT in Civil Society: World Summit on the Information Society, available at http://www.apc.org/books/policy_wsis_EN.pdf, September 2003, accessed April 17 , 2004, pp. 39-40.

28 The Association for Progressive Communications, p. 40.

29 The Association for Progressive Communications, p. 40.

30 Levine, p. 2.

31 Levine, p. 2.

32 Simon, "Conclusion," in Democracy and the Internet, pp. 96-102, p. 100.

33 Hewitt de Alcántara, p. 31.

34 The Association for Progressive Communications, p. 43.

35 The Association for Progressive Communications, p. 38.

36 Curtain, p. 23.

37 Norris, p. 13, 7.

38 Simon, “Conclusion,” p. 100.

39 Michael Edwards, Civil Society, Polity Press: Cambridge, UK, 2004, p. 66. 